\title{
THE INTRAFAMILIAL TRANSMISSION OF RHEUMATOID ARTHRITIS-IV
}

\author{
RECALLED PARENT-CHILD RELATIONS BY RHEUMATOID \\ ARTHRITICS AND CONTROLS
}

\author{
Ernest Harburg, Ph.D., Stanislav V. Kasl, Ph.D., \\ Joyce Tabor, M.A. and Sidney Cobb, M.D., M.P.H. \\ Institute for Social Research, Department of Psychology, The University of Michigan, \\ Ann Arbor, Michigan
}

(Received 21 December 1967; in revised form 26 August 1968)

\section{INTRODUCTION TO THE PROBLEM}

THE PURPOSE of this report is to describe how persons having rheumatoid arthritis differ from unaffected controls in their recall of early parent-child relations. The hypotheses examined in this study were mainly derived from research presented in several major reviews [1-3], as well as from case reports [4-6]. Cross-reference to research articles shows that findings specifically describing parent-child relations among rheumatoid arthritics seem restricted to a few, often cited studies. See Table 1 for a summary. These reports vary in many ways, such as the precision of the methods used or the age and sex composition of the study sample. Earlier reports tend to be based on clinical interviews of selected patients, mostly women, with no control groups [7-9]. More recent studies aim toward more explicitness in theory and precision in design [14-16]. All studies agree, however, in assuming the importance of studying the general hypothesis that the presence of rheumatoid arthritis in adults may be related to early punitive parent treatment inducing chronic resentment and inhibited anger, which later may act to promote, precipitate, or exacerbate the disease. This idea, of course, can be best tested with longitudinal designs; however, the majority of studies, including the present one, rely on testing for differences in recalled parent treatment as reported by adults with and without the disease. It might be noted in passing that this general hypothesis does not call for observations of relations between arthritic children and their mothers [11], where the childhood disease as well as the relationship of the mother with the sick child are probably different phenomena.

Our review of the literature in this area further indicates that most inquiries are focused on females and on their mothers [6, 14-16] and are often associated with reports of personality differences. These personality differences suggest that rheumatoid arthritics are inhibited in their expression of feelings, have difficulty with interpersonal relations, and are angry, but express aggression ineptly and rarely $[1,15-19]$. While most of such literature is expressed in psychoanalytic terms, the viewpoint of this study is explicitly a social-psychological one. Our central hypothesis is that adults with rheumatoid arthritis will with excessive frequency recall (1) their parents' authority as being 'arbitrary', and (2) their childhood response to such parent treatment as being 'resentment'. 


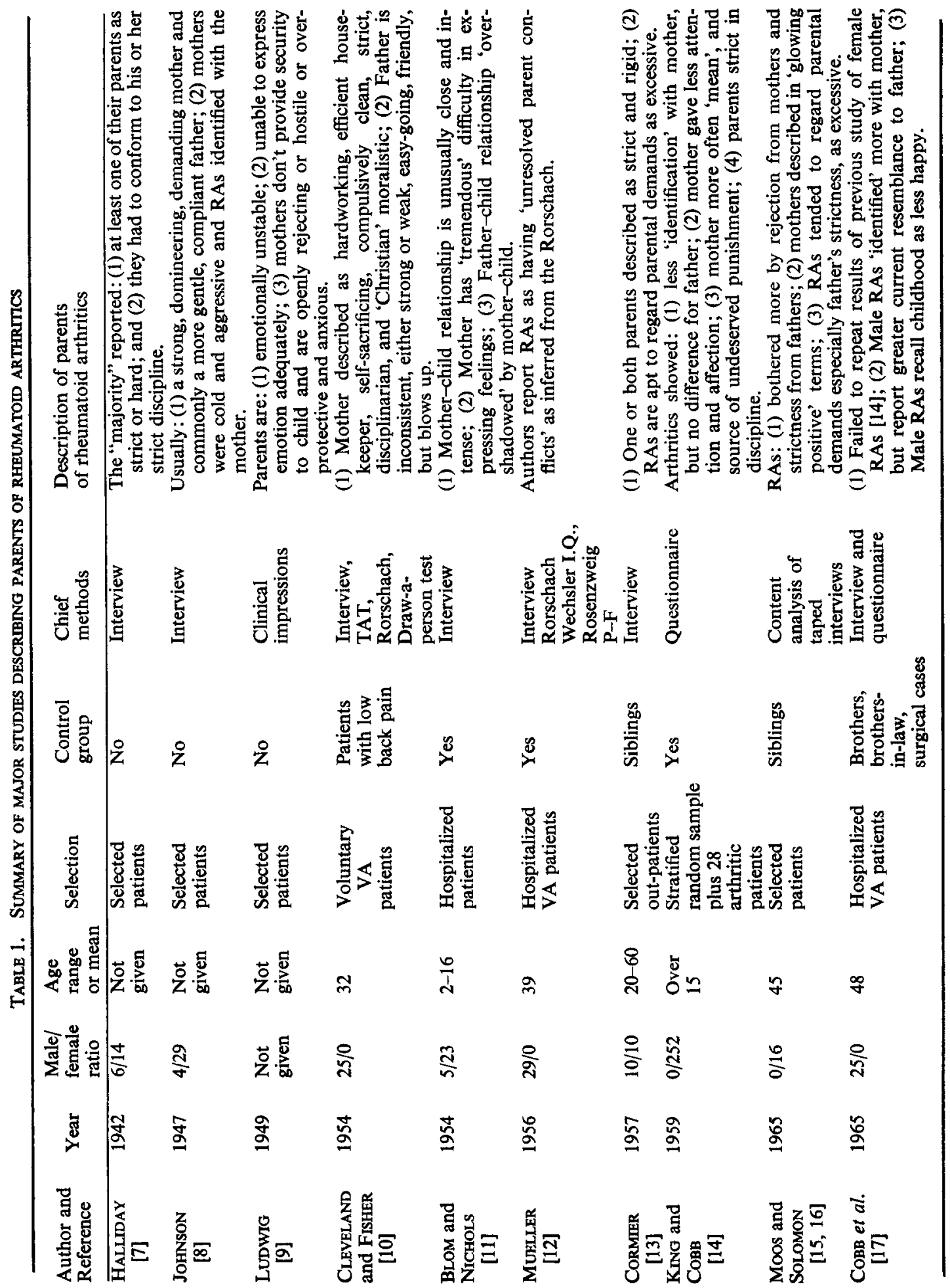


Let us now clarify the terms used in this focal hypothesis and elaborate on the theory involved. The idea of 'arbitrary authority' has been presented by Fromm $[20,21]$ as an expression of irrational authority, or more simply, the abuse of power in ways which restrict task efficiency and the healthy development of loving and trusting relations. Arbitrary authority can be viewed as a social frustration which produces instigation to aggression [22] and may, under certain conditions, lead to overt aggression. Experimental evidence suggests that when frustration is induced in an "arbitrary" way, more aggressive responses are likely to ensue than when frustration is perceived as 'reasonable' [23-26]. In the present study each parent is conceived of as a source of authority, whose style of authority ranges from reasonable to arbitrary. By arbitrary authority we refer to parent behavior which is perceived as being: (1) unreasonable; (2) high in aggression toward the child; (3) severe in discipline; (4) irritable; (5) high in control over the child's assertive behavior; and (6) somewhat distant. It is assumed that this style of authority acts as a condition of chronic frustration for the growing child, and that it in turn induces anger, hostility, and the urge to aggress against the offending parent. (The reader is referred to Buss [27] for clarifying these distinctions between anger, hostility, and aggression.)

There are, perhaps, several forms of adaptation by the 'subordinate' towards the source of such arbitrary authority. One such adaptation has been termed 'resentment'. According to SCHELER [28], resentment consists of intense hostile feelings which must not be expressed. Such hostile feelings arise from typically recurring situations felt to be injurious but beyond one's control, and are chiefly aroused in subordinates against figures of authority. Other observers [29-31] also agree that it is the felt loss of social and interpersonal rights which is the basic injury which creates and sustains resentment, and that, consequently, it is the perceived restoration of such rights, and not simply aggression against the authority figure which will resolve the resentment.

The perception of a parent as exerting arbitrary authority may set up a chronic condition in which resentment develops. 'The more arbitrary the parent's authority is perceived to be, the more intense should be the resentment. This resentment should be accompanied by only limited aggression because of the dependency of the child and the power of the parent. The social-psychological process of 'resenting' is therefore a composite of several perceptions and reactions by the child: (1) fear and hurt at parents' discipline; (2) covert blaming of parent for such punishment; (3) covertly resisting the parents' discipline; (4) feeling disaffected from the parent; but (5) not asserting oneself overtly against parental orders; (6) not displaying one's temper; and (7) feeling worthless and rejected.

As we shall see in the methods section below, the reactions listed under (2), (3) and (4) will be combined to form an index of covert hostility, while responses measured under (5) and (6) will comprise an index of the extent of overt aggressive behavior. The discrepancy between these covert and overt processes reflects the conflicting responses to parental authority. Specifically, when covert hostility to power or authority figures is more intense than overt aggression to those sources, this can be viewed as a complex response which this study will term 'resentment' [32]. We assume that such a coping style arises and is continuously reinforced through unchanging early parent-child interactions. It consists of a relatively stable, autonomous and consistent set of covert attitudes with contradictory overt responses. Thus a 
style of covert hostility and lack of overt aggressive responses may persist into the adult years by intermittent reinforcing contact between parent and child and by autistic arousal of images and anger [27, 31,32]. The aim of the present report is to describe how rheumatoid arthritics differ from controls in their adult recall of early parental authority and their childhood coping style of resentment, presented according to the sex of the child and of the parent.

\section{METHODS}

Inasmuch as the relevant details of the design of the study and some of the measurement techniques have been presented in the first two reports in this series, this section will be concerned with a description of the measures of recalled parent-child relations. The measurement procedures which were chosen were based, in part, on the previous work of HARBURG and MCGINN [33, 34].

In order to assess the recalled treatment of parents a modified semantic differential approach was used in which the respondent reacted on bipolar dimensions to 4 concepts: (1) and (2) How my father (mother) disciplined me when I was a child. (3) and (4) How my father (mother) taught me when I was a child. The bipolar dimensions include: mild-stern, gentle-hard, hard to annoy-easy to annoy, fairunfair, etc. There were numerous additional, specific questions about the nature of the parent-child and mother-father relationships, such as inquiries about resistance to parental orders or amount of overt conflict between parents. Using all the items, the following scales were constructed. The labels attached to these scales merely reflect the content covered by the items therein and say nothing about the scales' validity.

(1) Irritability of father (mother) - 5 items dealing with angry impatience. Ex.: Slow vs. Quick to get irritated.

(2) Severity of father (mother)-3 items dealing with severity of a parent's discipline. Ex.: Easy vs. Strict with me.

(3) Unreasonableness of father (mother) - 4 items dealing with perceived injustice of a parent's discipline. Ex.: Fair vs. Unfair.

(4) Aggression by father (mother)-3 items dealing with amount of aggression and physical punishment by a parent. Ex.: Never vs. Very often punished physically.

(5) Control by father (mother) -4 items dealing with strictness of a parent's control over respondent's attempts to resist or assert himself (herself). Ex.: How much did he (she) allow arguing in the family? Anytime vs. Not at all.

(6) Distance from father (mother) -4 items dealing with the amount of emotional distance in the relationship between the respondent and a parent. Ex.: Often vs. Rarely talked things over with me.

(7) Resistance to father (mother)-3 items dealing with covert reactions to a parent's disciplinary action. Ex.: Felt like giving in vs. Felt like resisting.

(8) Blamed father (mother)-1 item: Blamed self vs. Blamed father (mother) when punished.

(9) Disaffection from father (mother) -4 items dealing with amount of affectiondislike felt for each parent. Ex.: How much love did you feel for your father (mother)? Very much vs. Practically none. 
(10) Assertion to father (mother) -2 items, ex.: How often did you openly disagree with him (her)? Never vs. All the time.

(11) Overt temper-2 items, ex.: How often did you lose your temper? Never vs. Quite often.

(12) Childhood self-esteem-5 items dealing with feelings of worthlessness and rejection. Ex.: How often did you feel you were no good at all? Quite often vs. Never.

(13) Role model-5 items dealing with the relative influence of the mother vs. the father as an object of identification and admiration. Ex.: Which parent did you admire most? This index is based on the previous work of FUNKENSTEIN and KING $[14,35]$; a high score on this index indicates the mother was the important role model.

(14) Parental conflict-2 items, ex.: How often did they disagree with each other? Never vs. Quite often.

(15) Parental affection-2 items, ex.: How often did your father openly show love to your mother? Never vs. Very often.

(16) Dominant parent -5 items dealing with power and dominance relationships between the parents. Ex.: Which one would you say laid down the law for the family? Father definitely vs. Mother definitely.

In accordance with the theoretical discussion in the introductory section, some of the above scales were further combined to form composite indices. Specifically, scales 1-6 were combined to yield a total index of arbitary authority of father (mother); scales 7-9, an index of covert hostility towards father (mother); and scales 10-11, an index of overt aggressiveness towards father (mother). An index of discrepancy between covert hostility and overt aggressiveness will be referred to as resentment of father (mother).

It is worth noting that recent reviews of the theoretical literature on parental behavior [36, 37] have remarked upon the similarity of several conceptual models of parental behavior, all of which isolate love-hostility and autonomy-control as two crucial dimensions. In terms of these dimensions, the conceptualization of arbitrary authority used in this report is roughly equivalent to parental behavior which is both hostile and controlling, or what BECKER [36] calls "restrictiveness in a hostile context".

In order to remind the reader that rheumatoid arthritis was assessed by the RA measure we will use the abbreviation RA to mean categories 2 and 3 on the 4-point RA scale (see the second paper of this series for details about this scale).

\section{RESULTS}

The order of presentation of the data is guided both by our hypotheses and by the pattern of the actual findings. All initial analyses on differences between arthritics and non-arthritics took into account: (1) the two samples, National or Clinic; (2) the sex of the respondent; and (3) the sex of the parent whose behavior was recalled. As we shall see, the pattern of association with presence vs. absence of the disease is consistent and clear for females describing their mothers. The descriptions of fathers, whether by males or females, show no associations with the disease, while the males' descriptions of the mothers are less clearly related to RA. Accordingly, the presentation of results will emphasize the recalled perceptions of the mother's behavior and the respondent's remembered reactions to her. 
Table 2 gives the mean scores on the various scales descriptive of parent-child relations. For both men and women 2 tests of significance were carried out for each scale; significance of difference in means for RA vs. non-RA, and for National sample vs. Clinic sample respondents. The conventional 0.05 level of significance

Table 2. The association OF PRESENCE OR ABSENCE OF RHeUMatoid aRThRITIS WITH VARIABLES DESCRIPTIVE OF PARENT-CFILD RELATIONS

\begin{tabular}{|c|c|c|c|c|c|c|c|c|}
\hline \multirow{4}{*}{ Variable } & \multicolumn{4}{|c|}{ Women } & \multicolumn{4}{|c|}{ Men } \\
\hline & \multicolumn{4}{|c|}{$\begin{array}{c}\text { Significance } \\
\text { of difference } \\
\text { between }\end{array}$} & \multirow{2}{*}{\multicolumn{2}{|c|}{ Mean scores }} & \multicolumn{2}{|c|}{$\begin{array}{c}\text { Significance } \\
\text { of difference } \\
\text { between }\end{array}$} \\
\hline & \multicolumn{2}{|c|}{ Mean scores* } & \multirow[b]{2}{*}{$\begin{array}{l}\text { RA vs. } \\
\text { non-RA }\end{array}$} & \multirow{2}{*}{$\begin{array}{c}\text { National } \\
\text { vs. Clinic } \\
\text { samplest }\end{array}$} & & & \multirow[b]{2}{*}{$\begin{array}{l}\text { RA vs. } \\
\text { non-RA }\end{array}$} & \multirow{2}{*}{$\begin{array}{c}\text { National } \\
\text { vs. Clinic } \\
\text { samples }\end{array}$} \\
\hline & $\underset{\text { present }}{\mathbf{R A}}$ & $\begin{array}{c}\text { RA } \\
\text { absent }\end{array}$ & & & $\underset{\text { present }}{\mathbf{R A}}$ & $\begin{array}{l}\text { RA } \\
\text { absent }\end{array}$ & & \\
\hline \multicolumn{9}{|l|}{ Mother to child } \\
\hline Irritability & 3.41 & 2.94 & Yest & No & 2.27 & 2.88 & Yes & No \\
\hline Severity & 3.88 & 3.17 & Yes & No & 3.23 & 3.14 & No & Yes \\
\hline Unreasonableness & 2.21 & 1.85 & Yes & No & 1.58 & 1.78 & No & No \\
\hline Aggression & 2.78 & 2.52 & Yes & No & 2.33 & 2.44 & No & No \\
\hline Control & 3.48 & 3.25 & Yes & No & 3.05 & 3.01 & No & No \\
\hline Distance & 2.79 & 2.43 & No & No & 2.59 & 2.56 & No & No \\
\hline \multicolumn{9}{|l|}{ Child to mother } \\
\hline Resistance & 3.31 & 2.66 & Yes & No & 1.98 & 2.67 & Yes & No \\
\hline Blame & 3.56 & 2.97 & Yes & No & 1.94 & 2.62 & Yes & No \\
\hline Disaffection & 2.11 & 1.94 & Yes & No & 1.57 & 1.83 & No & No \\
\hline Assertion & 1.82 & 1.97 & No & No & 1.97 & 2.10 & No & No \\
\hline \multicolumn{9}{|l|}{ Father to child } \\
\hline Irritability & 3.91 & 3.69 & No & No & 3.32 & 3.61 & No & No \\
\hline Severity & 4.01 & 4.12 & No & No & 4.48 & 4.06 & No & No \\
\hline Unreasonableness & 2.32 & 2.08 & No & No & 1.81 & 2.20 & No & No \\
\hline Aggression & 2.35 & 2.22 & No & No & 2.48 & 2.56 & No & No \\
\hline Control & 3.50 & 3.47 & No & No & 3.15 & 3.10 & No & No \\
\hline Distance & 3.76 & 3.62 & No & No & 3.56 & 3.10 & No & No \\
\hline \multicolumn{9}{|l|}{ Child to father } \\
\hline Resistance & 3.16 & 3.27 & No & No & 2.83 & 3.04 & No & No \\
\hline Blame & 3.21 & 3.30 & No & No & 2.56 & 2.94 & No & Yes \\
\hline Disaffection & 2.38 & 2.21 & No & No & 2.17 & 2.14 & No & No \\
\hline Assertion & 1.67 & 1.69 & No & No & 1.83 & 1.96 & No & No \\
\hline Overt temper of child & 2.58 & 2.75 & Yes & No & 3.03 & 2.84 & No & No \\
\hline Childhood self-esteem & 3.79 & 4.10 & Yes & No & 4.12 & 4.13 & No & No \\
\hline Number of cases & 48 & 96 & & & 16 & 147 & & \\
\hline
\end{tabular}

*The higher the scores, the more of that behavior is reported.

fIn the national survey sample, $N=172$; in the clinic sample, $N=125$. No difference means that the same finding occurred in both samples.

$¥$ All differences are greater than the 0.05 level of significance.

was adopted. The findings in Table 2 may be summarized as follows: (1) In only 2 out of 44 tests of significance of difference between the National survey and the Clinic samples were the means "significantly" different, and in neither test does the variable involved show a significant association with RA. (2) Perceptions of fathers and recalled reactions to fathers' behavior show no association with disease, either in females or in males. (3) Women with RA recall their mothers in more negative 
terms and report greater covert hostility but somewhat less overt aggression towards her when they were children. (4) Men with RA do not yield a consistent picture: they recall their mothers in slightly more positive terms and report less covert hostility. (5) Women with RA report lower childhood self-esteem.

Since it is our intention to combine these scales (as indicated in the methods section), we shall next examine the intercorrelations among them. Table 3 presents the relevant data. Worth noting are the following points: (1) the intercorrelations

TABLE 3. INTERCORRELATIONS AMONO VARIABLES DESCRIPTIVE OF MOTHER-CHIID RELATIONS

\begin{tabular}{|c|c|c|c|c|c|c|c|c|c|c|c|}
\hline \multirow{2}{*}{$\begin{array}{c}\text { Respondent's recalled } \\
\text { treatment }\end{array}$} & \multirow[b]{2}{*}{ Age } & \multicolumn{2}{|c|}{ Women $(N=144)$} & \multirow[b]{2}{*}{1} & \multirow[b]{2}{*}{2} & \multirow[b]{2}{*}{3} & \multirow[b]{2}{*}{4} & \multirow[b]{2}{*}{5} & \multirow[b]{2}{*}{7} & \multirow[b]{2}{*}{8} & \multirow[b]{2}{*}{10} \\
\hline & & Education & Income & & & & & & & & \\
\hline \multicolumn{12}{|l|}{ Of mother to child: } \\
\hline 1. Irritability & -04 & -07 & -04 & $x$ & & & & & & & \\
\hline 2. Severity & -09 & -03 & -12 & 63 & $x$ & & & & & & \\
\hline 3. Unreasonableness & -12 & -07 & -10 & 68 & 51 & $x$ & & & & & \\
\hline 4. Aggression & -15 & -06 & 02 & 71 & 53 & 54 & $x$ & & & & \\
\hline 5. Control & 07 & -30 & -36 & 35 & 46 & 30 & 35 & $x$ & & & \\
\hline 6. Distance & -04 & 00 & -09 & 64 & 40 & 65 & 39 & 16 & & & \\
\hline \multicolumn{12}{|l|}{ Of child to mother: } \\
\hline 7. Resistance & -18 & 07 & -02 & & & & & & $x$ & & \\
\hline 8. Blame & -20 & 12 & 11 & & & & & & 51 & $x$ & \\
\hline 9. Disaffection & -18 & 05 & -08 & & & & & & 73 & 43 & \\
\hline 10. Assertion & -17 & 26 & 12 & & & & & & & & $x$ \\
\hline 11. Overt temper & -12 & 02 & 06 & & & & & & & & 47 \\
\hline \multicolumn{12}{|c|}{$\operatorname{Men}(N=163)$} \\
\hline $\begin{array}{l}\text { Respondent's recalled } \\
\text { treatment }\end{array}$ & Age & Education & Income & 1 & 2 & 3 & 4 & 5 & 7 & 8 & 10 \\
\hline \multicolumn{12}{|l|}{ Of mother to child: } \\
\hline 1. Irritability & -04 & -02 & -11 & $x$ & & & & & & & \\
\hline 2. Severity & -06 & -09 & -06 & 36 & $x$ & & & & & & \\
\hline 3. Unreasonableness & -07 & -06 & $\mathbf{0 0}$ & 47 & 36 & $x$ & & & & & \\
\hline 4. Aggression & -06 & -09 & 01 & 36 & 43 & 26 & $x$ & & & & \\
\hline 5. Control & -01 & -23 & -17 & 24 & 42 & 21 & 36 & $x$ & & & \\
\hline 6. Distance & -08 & -05 & -08 & 46 & 12 & 45 & 12 & 14 & & & \\
\hline \multicolumn{12}{|l|}{ Of child to mother: } \\
\hline 7. Resistance & -22 & 12 & 06 & & & & & & $x$ & & \\
\hline 8. Blame & -15 & 16 & 11 & & & & & & 37 & $x$ & \\
\hline 9. Disaffection & -04 & 08 & 02 & & & & & & 41 & 33 & \\
\hline 10. Assertion & -32 & 23 & 31 & & & & & & & & $x$ \\
\hline 11. Overt temper & 01 & 10 & 06 & & & & & & & & 20 \\
\hline
\end{tabular}

among the scales are higher for women than for men, and sufficiently high to permit combining them. (2) The correlations with age, education and family income are somewhat variable and certainly in the range where they account for a negligible amount of variance. Only 4 out of 66 correlations have an absolute value over 0.30 ; the correlations of these demographic variables with the combined summary indices would, of course, be very low. The correlations are presented primarily to give the reader additional information about the scales, e.g. to demonstrate the absence of a social class effect. Adjustments for age, education, or income would be unnecessary in any case since the arthritics do not differ on these variables from the non-arthritics. (3) the intercorrelations presented in Table 3 are not significantly 
changed when one controls for presence vs. absence of RA. (4) The intercorrelations for scales reflecting father's behavior and recalled reactions to father (not given in Table 3) show the same average level of association and same sex difference as the just examined scales describing the mother-child relationship.

The next step in the analysis was to construct the summary indices described at the end of the methods section. In order to accomplish this, all raw sccres on all the scales were first converted into standard or z-scores before being summed. The associations of these summary indices with presence vs. absence of RA are given in Table 4. However, before we examine the actual findings, a word of explanation

Table 4. The association OF RHEUMATOId ARTHRITIS WITH SUMMARY INDiCES OF PARENT-CHILD RELATIONSHIP

\begin{tabular}{|c|c|c|c|c|}
\hline \multirow[b]{2}{*}{$\begin{array}{l}\text { Variable being related to } \\
\text { presence vs. absence of } R A\end{array}$} & \multicolumn{2}{|c|}{ Women $(N=144)$} & \multicolumn{2}{|c|}{$\operatorname{Men}(N=163)$} \\
\hline & $\begin{array}{l}\text { Degree of } \\
\text { association* }\end{array}$ & $\begin{array}{l}\text { Significance } \\
\text { of } \\
\text { association }\end{array}$ & $\begin{array}{l}\text { Degree of } \\
\text { association }\end{array}$ & $\begin{array}{l}\text { Significance } \\
\text { of } \\
\text { association }\end{array}$ \\
\hline Arbitrary authority of mother & $\begin{array}{l}\text { Tau }=0.25 \\
\text { Gamma }=0.43\end{array}$ & $<0.001$ & $\begin{array}{l}\text { Tau }=-0.11 \\
\text { Gamma }=-0.36\end{array}$ & n.s. \\
\hline Arbitrary authority of father & $\begin{array}{l}\text { Tau }=0.09 \\
\text { Gamma }=0.16\end{array}$ & n.s. & $\begin{array}{l}\text { Tau }=0.00 \\
\text { Gamma }=0.01\end{array}$ & n.s. \\
\hline Covert hostility towards mother & $\begin{array}{l}\mathrm{Tau}=0.24 \\
\mathrm{Gamma}=0.42\end{array}$ & $<0.005$ & $\begin{array}{l}\text { Tau }=-0.25 \\
\text { Gamma }=-0.63\end{array}$ & $<0.001$ \\
\hline $\begin{array}{l}\text { Overt aggressiveness towards } \\
\text { mother }\end{array}$ & $\begin{array}{l}\text { Tau }=-0.19 \\
\text { Gamma }=-0.35\end{array}$ & $<0.01$ & $\begin{array}{l}\mathrm{Tau}=0.04 \\
\text { Gamma }=0.14\end{array}$ & n.s. \\
\hline $\begin{array}{l}\text { Resentment of mother (covert } \\
\text { hostility minus overt aggressive- } \\
\text { ness) }\end{array}$ & $\begin{array}{l}\mathrm{Tau}=0.25 \\
\text { Gamma }=0.43\end{array}$ & $<0.001$ & $\begin{array}{l}\text { Tau }=-0.25 \\
\text { Gamma }=-0.63\end{array}$ & $<0.001$ \\
\hline
\end{tabular}

*Positive correlations mean that arthritics score higher than non-arthritics on a particular variable.

about the choice of statistics seems in order. In describing the differences between arthritics and non-arthritics we want to choose a statistic which yields a measure of amount of association as well as a test of significance. In view of the fact that one of the variables-presence vs. absence of RA - is a dichotomous one, and that the summary indices yield a skewed distribution of scores, it was decided to use 2 measures of association neither of which requires interval scale properties: (1) KENDALL's $\mathrm{Tau}_{\mathrm{B}}[38,39]$, a rank order correlation with ties; (2) GoOdMAN and KRUSKAL's gamma [40], an index specifically developed for data arranged into ordered classes. The gamma indicates the degree to which the relation between two variables is a monotone one. The test of significance is the same for both and incorporates a correction for continuity [41]. However, because they are based on different assumptions (in their treatment of ties) the gamma will generally yield higher values than the Tau; this disparity will be especially high when the split on the dichotomous variable is particularly uneven. The reader may assume that the best estimate of the actual amount of association would be somewhere between the Tau and the gamma values. This is because: (1) When a product-moment correlation and a Tau are computed on the same set of artificial data, the Tau is the one which yields a lower value. In our data the Tau thus represents the lower bound of an estimate of strength and association. (2) A computation of biserial correlations between presence vs. absence of RA and the variables in Table 4 yielded values approximately half-way between the Taus and the gammas. 
The following remarks would seem to adequately summarize the results presented in Table 4: (1) RA women recall their mothers as having exercised more arbitrary authority, report that they felt more covert hostility towards her, but exhibited less overt aggressiveness toward her. The amount of resentment of mother, excess of covert hostility over overt expression of aggression, is particularly striking among the arthritic women; (2) RA men show a nonsignificant tendency to recall their mothers as less arbitrary, report that they felt less covert hostility towards her, and were less likely to resent her, i.e. more likely to express themselves with overt aggression rather than feel covert hostility towards her; and (3) The recall of father's authority as arbitrary was unrelated to RA in either women or men.

In a secondary analysis, the measures of association for the variables in Table 4 were recomputed after persons with some evidence of arthritis, but not enough to make them positive on the RA measure ( 20 women and 19 men), were taken out of the ' $\mathrm{RA}$ absent' category, where they are otherwise placed. The resultant Tau and gamma values for the significant associations all became somewhat higher. For example, the Tau of 0.25 between Resentment of Mother and RA in women became Tau of 0.34 . It thus appears that a more precise differentiation of the RA and non-RA categories also leads to a sharper separation along the psychological variables.

'Arbitrary authority of father' is clearly unrelated to presence or absence of RA in our samples. Moreover, it is also independent of 'arbitrary authority of mother'; the correlations between the 2 indices are 0.03 and -0.06 for men and women, respectively. On the other hand 'arbitrary authority of mother' is fairly highly correlated with 'covert hostility towards mother' $(r=0.53$ for men and $r=0.66$ for women), moderately correlated with 'resentment of mother' ( $r=0.41$ and $r=0.46)$ but not significantly correlated with 'overt aggressiveness towards mother' $(r=0.06$ and $r=0.15$ ).

The fact that some of these variables are intercorrelated raises the following problem with regard to Table 4: are the associations of 'covert hostility and resentment' with presence or absence of RA simply due to the fact that they are both related to 'arbitrary authority of mother', which in turn is related to RA? For example, is it possible that arthritic women report more covert hostility towards their mothers simply because they recall them as more arbitrary; but once the mothers arc seen as highly arbitrary, the RA women react with no more covert hostility than those non-arthritic women who also recall their mothers as highly arbitrary? In order to answer such questions the following procedure was adopted: the data on the relevant indices for the non-arthritic men and women were used to determine the linear regression equation which would yield predicted 'covert hostility and resentment' scores for each score on 'arbitrary authority of mother'. The same regression equation was then applied to the arthritic subjects to compute the predicted scores on the same two indices, but, of course, their own scores on 'arbitrary authority of mother' was used. The predicted and actual scores were then compared. Among the arthritic women, 33 out of $48(p<0.005)$ had higher actual than predicted scores on 'covert hostility' and 32 out of $48(p=0.01)$ had higher actual than predicted scores on 'resentment'. For the 16 arthritic men the differences between actual and predicted scores were evaluated by a $t$-test and showed that these men were lower than predicted both on 'covert hostility' $(p<0.001)$ and 'resentment' $(p<0.05)$. 
These findings thus indicate that the reported reactions of the arthritics to their mothers are different than the reactions of the non-arthritics above and beyond the differences in reported mother's behavior.

Another inportant question is raised by Table 4 . The indices of 'arbitrary authority of father and of mother' are measures of recalled parental behavior and are subject to distortions of memory and of current feelings of the respondent. How do we know that the indices are more than autistic distortions stemming from the respondent's current anger and hostility? Three points can be mentioned in answering this question:

(1) There were 44 sib pairs on whom we had parent perception data which independently described the same parents. The agreement on recalling father's authority was $r=0.44$ ( $p<0.001)$, while for mother's authority $r=0.40(p<0.005)$. This is a moderate amount of agreement and, of course, we do not know to what extent distortions of memory do contribute to the disagreement between sib pairs, inasmuch as true differences in the way the parent had treated the 2 sib respondents would also be a factor lowering the correlation. Since only 18 of the 44 sib pairs are of the same sex, this point is especially relevant should a parent indeed tend to express his (her) authority differently over a son than over a daughter. For example, the correlation of 0.40 reflecting sibling agreement on recall of mother's authority becomes $r=0.55$ when computed only on the 18 pairs of same-sexed siblings.

(2) A measure of frequency of current anger-irritation was constructed in order to examine its association with RA (see the next report in this series where the data on mental health and affective components of RA are presented). There are 7 items in this index and they were scattered throughout the three interviews. A typical item is: "How often do you feel irritated or annoyed?" This measure was correlated with 'arbitrary authority of mother' in 2 ways: (a) The amount and direction of disagreement between each pair of sibs, describing their mother's behavior, was computed and correlated with frequency of current anger-irritation of each respondent. The obtained correlation was -0.08 (n.s.), demonstrating that there was no tendency for the more angry adult respondents to exaggerate the mother's arbitrariness; if anything, the tendency is in the opposite direction. (b) The same measure of disagreement was correlated with a score reflecting the difference in frequency of current anger-irritation between the two siblings. The resulting correlation was 0.13 (n.s.), indicating that there is a non-significant, negligible tendency for the more angry sibling to recall his (her) mother as more arbitrary.

(3) In a separate report (42) it was shown that the 2 indices, "arbitrary authority of father and of mother', are related to the amount of status incongruence and discrepancy characterizing the parents' marriage. To the extent that status incongruence is an antecedent variable, the report of the behavior of parents is partly anchored in an objective variable and is thus not totally at the mercy of the 'autistic distortion' hypothesis.

Table 5 gives a summary of the major findings so far discussed. The scores on two scales, 'arbitrary authority of mother and resentment of mother' ('covert hostility minus overt aggressiveness'), were summed for each respondent to form a composite distribution of scores which were then dichotomized at the median separately for each sex. Thus a person with a high score on this composite index reported that his mother had been highly arbitrary and/or recalled having resented her a great deal. 
TABle 5. THE association OF RHEUMATOID ARTHRITIS WITH A COMPOSITE SCORE ON ARBITRARY AUTHORTY OF MOTHER AND RESENTMENT OF MOTHER

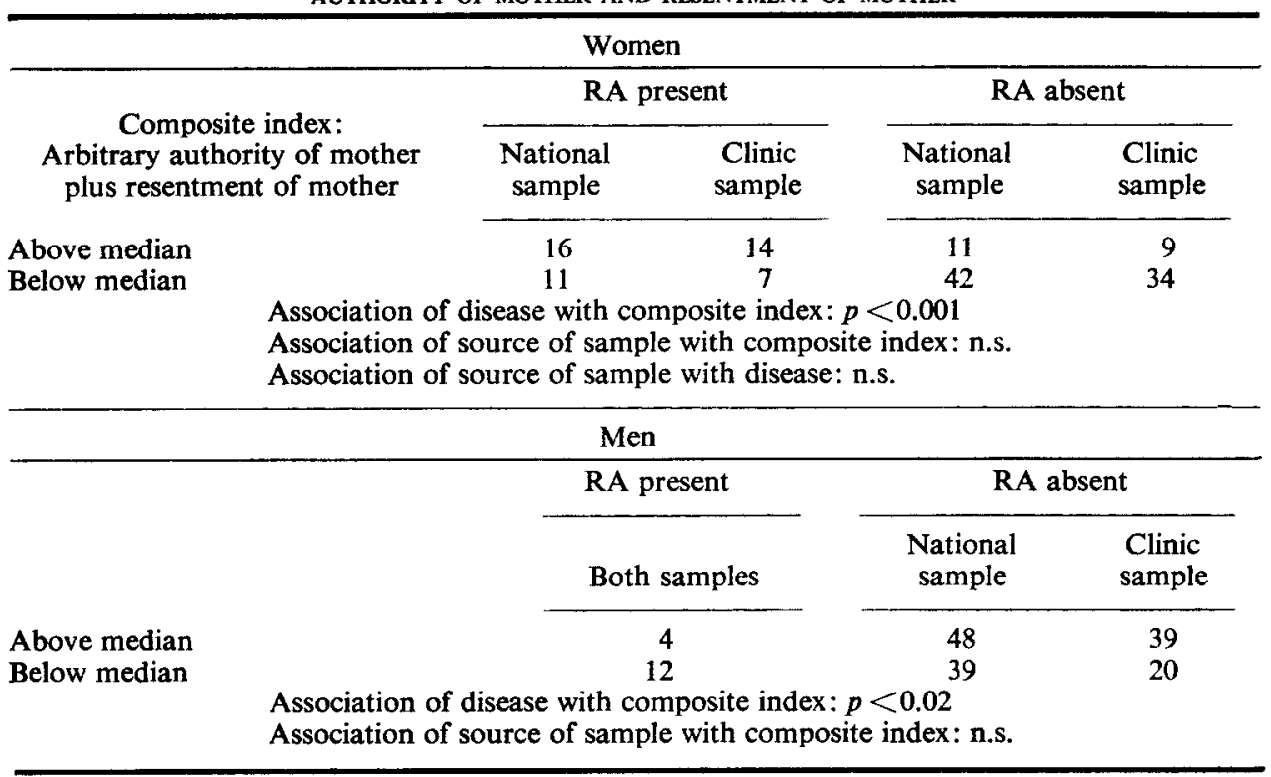

The table clearly demonstrates that for women the findings for National and Clinic samples are quite comparable. There were too few male arthritics to permit a meaningful comparison between the 2 samples. It should also be obvious that the sex difference is highly significant: the composite index relates to the presence vs. absence of RA differently in men than it does in women. We shall return to this sex difference in the discussion section.

Further evidence from the questionnaire supports the above findings of differences in reactions to mother's behavior between arthritic and non-arthritic women. Two

TABLE 6. TYPES OF RESPONSE TO MOTHER'S AND FATHER'S ANGER AMONG FEMALE ARTHRITICS AND NON-ARTHRITICS

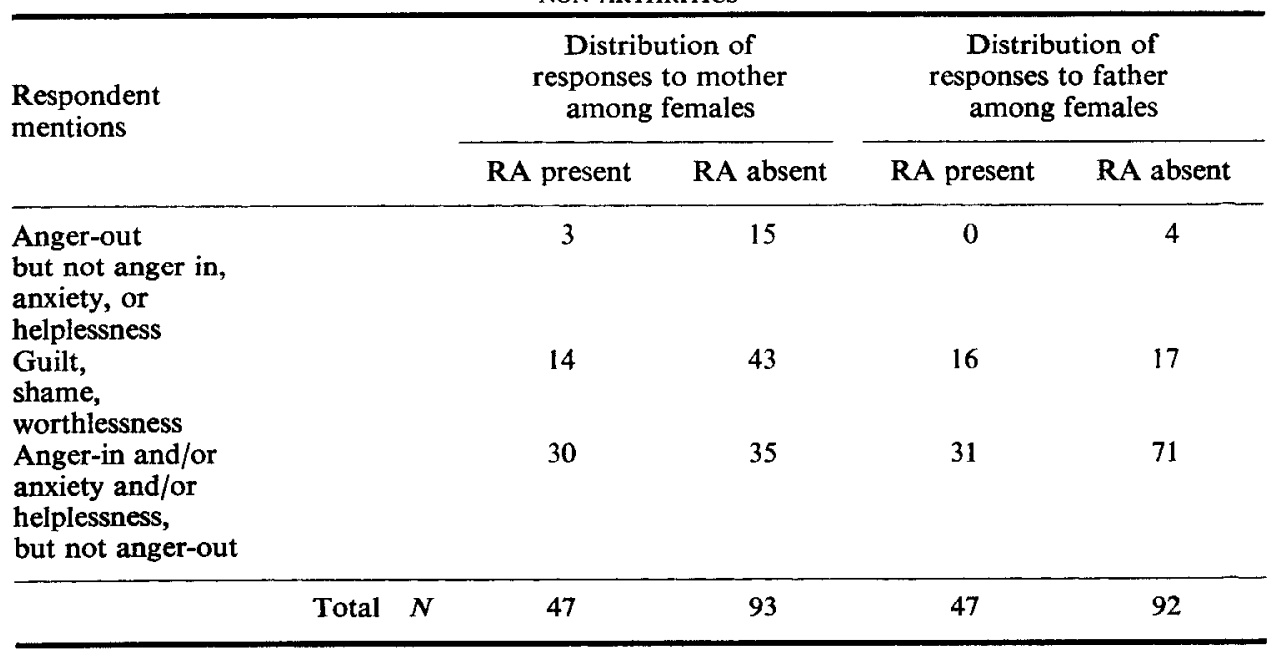


questions were asked: "When your mother (your father) got angry at you, how did you feel?" Responses were coded into the following categories: (1) Anger-out: would get angry and would express it; (2) Anger-in: would be angry but would not show it; (3) Anxious or nervous; (4) Helpless, overpowered or hurt; (5) Guilty, ashamed or worthless. The relevant data are presented in Table 6 . It can be seen that arthritic women are more likely to react to mother's anger with anger-in, anxiety or helplessness, while more anger-out and guilt responses are given by the non-RA women. The women's reactions to father's anger showed no significant association with arthritis. However, it is worth noting that when the women's reaction of anger-in, anxiety and/or helplessness is examined by sex of parent there is a significant difference between RA's and non-RA's. Specifically among non-RA's, 43 per cent report this response to father but not to mother while only 2 per cent give it to mother but not to father. Among the RA's, only 17 per cent give this response to father but not to mother and 13 per cent give it to mother but not to father. This suggests that the excess response of anger-in, anxiety and/or helplessness of the RA woman is not general but rather specific to the mother. The data on the males revealed no significant associations between RA and reaction to parents' anger.

One additional bit of evidence, this one on dating behavior, is also consistent with the notion of lowered assertiveness in the childhood and adolescent behavior of the arthritic women. Two questions were asked: "At what age did your parents allow you to go out with boys?" and "At what age did you actually go out with boys?" While there were no differences on the first question, comparisons on the second item showed that arthritic women were somewhat more likely to go out at a later age than allowed, while the non-arthritic women reported slightly more often that they went out sooner than allowed $(p<0.03)$.

In Table 2 it was shown, but not discussed in the text, that the arthritic women were significantly lower on childhood self-esteem than the non-arthritic women: they recalled stronger childhood feelings of worthlessness ard rejection (Tau $=-0.18$ or gamma $=-0.34, p<0.02$ ). In the theoretical section this was predicted as a consequence of mother's greater arbitrariness. However, it is also interesting to note that the reactions to mother's arbitrariness were more closely related to childhood self-esteem for the arthritic women than for the non-arthitic ones: the greater the resentment (excess of covert hostility over overt aggressiveness) towards mothers, the lower the self-esteem among the arthritics $(r-0.50, p<0.001)$, but not so for the non-arthritics $(r=-0.14$, n.s.). The difference in the correlations is significant $(p<0.02)$. One interpretation here would be that for the non-arthritics the balance between covert hostility and overt aggressiveness is largely a matter of coping with mother's arbitrariness, while for the arthitics it has strong implications for selfesteem and feelings of being unworthy.

The reader will recall that in the methods section additional measures describing parental behavior were constructed. We shall now turn briefly to these and will consider, first of all, the role model index. This measure reflects the relative influence of the mother vs. the father, as an object of identification and admiration. No association was found between RA and this index either men or in women. At first view, this appears to be a straightforward finding of no differences; however, since there is a substantial negative correlation between mother's arbitrariness and the likelihood of her being the role model, $r=-0.45$ among all women respondents 
and $r=-0.55$ among the non-arthritic women, we would expect the arthritic women, whose mothers are more arbitrary, to be less likely to report such mothers as role models. In order to evaluate this discrepancy between what the Role Model index scores ought to be, given the level of mother's arbitrariness, and what they actually are for the arthritic women, the same procedure was adopted as the one outlined for testing the notion that the RA women's covert hostility toward their mothers was even higher than would be predicted from the mothers' higher arbitrariness. This procedure yielded significant differences between obtained and predicted scores $(p<0.03)$, thus demonstrating that the RA women were apparently unable to cope with their mothers' arbitrariness by rejecting her as a role model, as did those nonRA wcmen whose mothers were comparably severe in arbitrary authority. (ANNA FREUD's [43] term, "identification with the aggressor" might not be inappropriate here).

The next pair of measures to be examined are those labelled Parent Conflict and Parent Affection, two short indices describing the behavior of the parents towards each other. Neither among the men nor the women were there any significant differences in the means for those with and without RA. However, there was an interesting difference in the way the 'conflict and affection' variables were related to each other; among non-RA women the two variables are negatively correlated $(\mathrm{Tau}=-0.30$, gamma $=-0.52, p<0.005)$, while among the RA women the correlation is, surprisingly, positive (Tau $=0.33$, gamma $=0.58, p<0.02$ ). The difference in the correlations is highly significant $(p<0.001)$. The present writers could offer no explanation of this finding other than pure speculation; however, it is sufficiently striking to be tagged for future reference. Another finding which lacks immediate theoretical significance and will be simply noted in passing, is the difference between male arthritics and non-arthritics on the last index of parental behavior labeled dominant parent; the male RA's were more likely to see their father as the dominant parent $(\mathrm{Tau}=0.18$, gamma $=0.52, p<0.02)$ than were the non-RA males. There were no such differences among the women.

\section{DISCUSSION}

The study is based on retrospective data gathered in three interviews with male and female adults drawn from a National and a Clinic sample. The measures which are developed are practically free of biases due to age, social class, and sample. The data on perception of parents show that there is fair agreement between independent repoits of siblings, and that they are free of possible biases due to respondent's current level of anger-irritation.

A review of the relevant literature on the possible role of parental behavior and parent--child interactions in the eventual development of arthritis in the offspring led to a theoretical formulation which became a guiding framework for the present study. This theory evolves from a broad social-psychological viewpoint; it allows for differential predictions, depending on the sex of the parent as well as the sex of the adult respondent with rheumatoid arthritis, and it singles out for emphasis the relation between the mother and the female offspring. The central hypothesis is that adults with rheumatoid disease will, more often than controls, recall their parents as being arbitrary and their own childhood responses as being that of resent- 
ment. The more intense the recall of arbitrary authority, the more intense the resentment.

The results offer strong support for the hypothesized relationships for women with RA, but not for the men. Women with RA, in contrast to controls recalled their mothers as having exercised more arbitrary authority, and reported that they had felt more covert hostility towards their mothers, but had exhibited less overt aggressiveness toward them. Their recall of their fathers, however, showed no differences. These results, based on questionnaire items combined into various indices, were supported by additional data obtained by coding answers to open-ended questions dealing with similar topics. In addition to these findings which are central to the hypothesis, there were other results which support the total picture: (a) RA women had lower childhood self-esteem, i.e. more feelings of rejection and worthlessness, than their controls and their lower self-esteem was more closely tied up with an inability to express their anger overtly; (b) RA women admired and identified with their mothers no less frequently than non-arthritic women, even though such mothers were considerably higher on arbitrary authority.

The data on the men failed to support the theoretical expectations formulated at the beginning of the study. It is true that because the instruments developed were based more on theory about the mother-daughter relationship and because the number of arthritic men was so small, the conditions for testing the hypotheses about arthritic men were less than optimal. Nevertheless, if one allows for this, the significant relationships which were obtained still fail to support the original hypothesis: compared to their controls, RA men tended to describe their mothers as being less arbitrary, reported less hostility towards them and were more likely to favor overt to covert expression of their anger towards them. There were again no differences in their perceptions of their fathers. Thus our data indicate a clear sex difference among rheumatoid arthritics in their recall of treatment by their parents.

In conclusion, it might be suggested that in the future, more attention needs to be paid to differences in the behavior between the 2 parents and then relate these to the parent-child variables studied. It is possible that the dynamics of rheumatoid arthritis in males will become clearer when the nature of the mother-son and fatherson relaticnships are examined jointly with the mother-father relationship. SLATER's hypothesis [44] that extreme "role differentiation" between parents may be a factor in producing disturbed parent-child relationships is an illustration of how the behavior of the parents towards each other can modify the parent-child line of influence.

\section{SUMMARY}

The study is based on data from three survey interviews, taken four months apart, on adults over $30 \mathrm{yr}$ old. Subjects were drawn both from a National sample of the United States and a Clinic sample in Ann Arbor. The results indicate that females with rheumatoid arthritis, in contrast to controls without RA, reported mothers who were more arbitıary in authority, and toward whom the daughter felt more covert hostility but showed less overt aggressiveness. Nevertheless, RA females rated their mothers as strong role models as did the non-RA women. No such differences with the father were evident. Female RA's also showed the lowest 
childhood self-esteem score, compared to female controls and males. By contrast, RA males reported a more pesitive image of the mother toward whom less covert hostility was felt. No such differences in the father-child relations were seen.

\section{REFERENCES}

1. KING, S. H.: Psychosocial factors associated with rheumatoid arthritis: An evaluation of the literature. J. chron. Dis. 2, 287, 1955.

2. Moos, R. H.: Personality factors associated with rheumatoid arthritis: a review. J. chron. Dis. 17, 41, 1964.

3. Scotch, N. A. and Geiger, H. J.: The epidemiology of rheumatoid arthritis: A review with special attention to social factors. J. chron. Dis. 15, 1037, 1962.

4. French, T. M. and ShapiRo, L. B.: The use of dream analysis in psychosomatic research. Psychosom. Med. 11, 110, 1949.

5. Grinker, R. R. and Robbins, F. P.: Psychosomatic Case Book. Blakiston, New York, 1954.

6. Scotr, A.: Woman with Arthritis. Abelard-Schuman, London, $195 \%$

7. Halliday, J. L.: Psychological aspects of rheumatoid arthritis. Proc. K. Soc. Med. 35, 455, 1942.

8. Johnson, A., Shapiro, L. B. and Alexander, F.: Preliminary report on a psychosomatic study of rheumatoid arthritis. Psychosom. Med. 9, 295, 1947.

9. LuDwIG, A. D.: Emotional factors in rheumatoid arthritis: Their bearing on the care and rehabilitation of the patient. Physiother. Rev. 29, 339, 1949.

10. Cleveland, S. E. and Fisher, S.: Behavior and unconscious fantasies of patients with rheumatoid arthritis. Psychosom. Med. 16, 327, 1954.

11. Blom, G. E. and Nicholls, G.: Emotional factors in children with rheumatoid arthritis. Am. J. Orthopsychiat. 24, 588, 1954.

12. Mueller, A. D. and Lefkovits, A. M.: Personality structure and dynamics cf patients with rheumatoid arthritis. J. clin. P.ychol. 12, 143, 1950.

13. Cormier, B. M., Wittkower, E. D., Marcotte, V. and Forget, F.: Psychological aspects of rheumatoid arthritis. Can. med. Ass. J. 77, 533, 1957.

14. KING, S. H. and СовB, S.: Psychosocial studies of rheumatoid arthritis: Parental factors compared in cases and controls. Arthritis Rhuem. 2, 322, 1959.

15. Moos, R. H. and Solomon, G. F.: Psychological comparisons between rheumatoid arthritics and their siblings: I. Personality test and interview rating data. Psychosom. Med. 27, 135, 1965.

16. Moos, R. H. and Solomon, G. F.: Psychological comparisons between rheumatoid arthritics and their siblings: II. Content analysis of interviews. Psychosom. Med. 27, 150, 1965.

17. Cobr, S., Kasl, S. V., Chen, E. and Christenfeld, R.: Some psychological and social characteristics of patients hospitalized for rheumatoid arthritis, hypertension, and duodenal ulcer. J. chron. Dis. 18, 1259, 1965.

18. Cleveland, S. E. and Fisher, S.: A comparison of psychological characteristics and physiological reactivity in ulcer and rheumatoid arthritic groups: I. Psychological measures. Psychosom. Med. 22, 283, 1960.

19. Совв, S.: Intrafamilial transmission of rheumatoid arthritis. In: Genetics and Chronic Diseases, (Eds. Neel, V. J., Shaw, M. W. and Schull, W. J.) U.S. Government Printing Office, Washington, D.C., 1965.

20. Fromm, E.: Man for Himself. Rinehart, New York, 1947.

21. Fromm, E.: The Sane Soriety. Rinehart, New York, 1955.

22. Dollard, J., Doob, L. W., Miller, N. E., Mowrer, D. H. and Sears, R. R.: Frustration and Aggression. Yale University Press, New Haven, 1939.

23. Allison, J. and HưNT, D. E.: Social desirability and expression of aggression under varying conditions of frustration. J. consult. Psychol. 23, 528, 1959.

24. CoHEN, A. R.: Social norms, arbitrariness of frustration, and status of the agent of frustration in the frustration-aggression hypothesis. J. abnorm. soc. Psychol. 51, 222, 1955.

25. PAstore, N.: The role of arbitrariness in the frustration-aggression hypothesis. J. abnorm. soc. Psychol. 47, 728, 1952.

26. Rothaus, P. and WORChel, P.: The inhibition of aggression under nonarbitrary frustration. J. Personality 28, 108, 1960.

27. Buss, A. H.: The Psychology of Aggression. Wiley, New York, 1961.

28. SCHELER, M.: Ressentiment. The Free Press, Glencoe, Ill., 1961.

29. Heder, F.: The Psychology of Interpersonal Relations. Wiley, New York, 1958. 
30. Horwrrz, M.: Psychological needs as a function of social environments. In: The State of Social Sciences. (Ed. WHITE, L. D.) The University of Chicago Press, Chicago, 1956.

31. NewComb, T. M.: Autistic hostility and social reality. Hum. Relat. 1, 3, 1947.

32. HARBURG, E.: Covert hostility: Its social origins and relationship with overt compliance. Unpublished Ph.D. thesis, University of Michigan, 1962.

33. Harburg, E., MCGinn, N. F. and Wigle, J. B.: Recalled treatment by parents among college males and blood pressure levels vs. reactivity. J. Psychosom. Res. 9, 173, 1965.

34. MCGinn, N. F., HARBurg, E. and Julrus, S.: Blood pressure reactivity and recall of treatment by parents. J. Personality Soc. Psychol. 1, 147, 1965.

35. Funkenstein, D. H., KING, S. H. and DRoletTE, M. E.: Mastery of Stress. Harvard University Press, Cambridge, 1957.

36. BeCKer, W. C.: Consequences of different kinds of parental discipline. In: Review of Child Development Research, Vol. 1. (Eds. Hoffman, M. L. and Hoffman, L. W.) Russell Sage Foundation, New York, 1964.

37. SCHAEFER, E. S.: Converging conceptual models for maternal behavior and for child behavior. In: Parental Attitudes and Child Behavior. (Ed. Glidewell, J. C.) Thomas, Springfield, Ill., 1961.

38. Kendall, M. G.: Rank Correlation Methods. 2nd ed., Griffin, London, 1955.

39. Whitfield, J. W.: Rank correlation between two variables, one of which is ranked, the other dichotomous. Biometrika 34, 292, 1947.

40. GoOdman, L. A. and KRUSKAL, W. H.: Measure of association for crossclassifications. $\boldsymbol{J}$. $\mathbf{A m}$. Stat. Ass. 49, 732, 1954.

41. Hays, W. L.: Statistics for Psychologists. Holt, Rinehart \& Winston, New York, 1963.

42. KASL, S. V. and СовB, S.: The effects of parental status incongruence and discrepancy on physical and mental health of the adult offspring. J. Personality Soc. Psychol. Monogr. 7 (2) (Whole No. 642), 1, 1967.

43. Freud, A.: The Ego and the Mechanisms of Defense. Hogarth Press, London, 1936.

44. Slater, P. E.: Parental role differentiation. Am. J. Sociol. 67, 296, 1961. 